\title{
PERSPECTIVAS
}

Artigo convidado

DOI: http://dx.doi.org/10.1590/So034-759020170609

\section{POR UMA PESQUISA QUE FAÇA SENTIDO}

A questão do impacto social da pesquisa científica é um tema de relevância na agenda atual não só no Brasil, mas internacionalmente, e é foco de preocupação não apenas dos cientistas, mas da sociedade em geral. Entre os cientistas, destacam-se os questionamentos que emergem sobretudo a partir dos anos 1970 e 1980, tendo como estopim a "Guerra das Ciências" (Santos, 2004), e que promovem uma desnaturalização da ciência como espaço de neutralidade e enclave autônomo e descolado da sociedade e suas influências (políticas, ideológicas, religiosas etc.). Já do lado da sociedade, diante dos inúmeros e complexos problemas socioambientais do nosso tempo, percebe-se um clamor para que a ciência seja um espaço para construção de novas compreensões sobre o presente e o passado, e para pensar novos futuros possíveis.

No campo da Administração, a discussão sobre o impacto social da ciência está normalmente associada ao debate sobre a aplicação do conhecimento e seus efeitos, aspecto sem dúvida relevante. Entretanto, diante dos desafios atuais, faz-se necessário discutir a questão do impacto social para além da funcionalidade da pesquisa científica e sua aplicação no campo prático. Para nós, a questão do impacto social da pesquisa diz respeito a questões mais amplas, como a própria relação entre ciência e a sociedade, à prática científica e ao papel da ciência como vetor de transformação da realidade. Nesse sentido, é preciso rediscutir também o papel da ciência da Administração e suas consequências, seja no âmbito público, privado ou das organizações da sociedade civil.

GRAZIELA DIAS ALPERSTEDT

gradial@gmail.com

Professora da Universidade do Estado de Santa Catarina, Centro de Ciências da Administração e Socioeconômicas - Florianópolis $-S C$, Brasil

\section{CAROLINA ANDION}

andion.esag@gmail.com

Professora da Universidade do Estado de Santa Catarina, Centro de Ciências da Administração e Socioeconômicas - Florianópolis -SC, Brasil

\section{MAS QUAL CIÊNCIA DA ADMINISTRAÇÃO?}

Ainda hoje, coloca-se a questão de a Administração ser ou não ser considerada uma ciência. Esse questionamento relaciona-se à ideia de que uma ciência aplicada e tão contaminada com as práticas não seria digna de ser considerada ciência. Tal concepção tem origem no debate clássico nos âmbitos da filosofia da ciência, desde Francis Bacon e René Descartes até Talcott Parsons, e da sociologia do conhecimento, por exemplo, com Weber (1973) e Merton (1967). Esse debate foi essencial para fundar as bases de uma compreensão das ciências sociais como ciências menores, por não terem um alto grau de autonomia em relação a outros domínios do saber, como a política, por exemplo. Essa compreensão da autonomia científica (como uma capacidade de estar imune à influência dos demais campos de saberes) naturaliza a ideia de que a boa ciência é aquela que se 
encapsula em relação à sociedade, formando uma espécie de proteção às influências que possam ameaçar a neutralidade e a independência científicas.

Essa visão predominou até mais recentemente e está presente em autores mais contemporâneos que discutem a história das ciências, como Kuhn (1987)), ou a sociologia da ciência (Bourdieu, 2001). Em suma, tal concepção da autonomia científica está ligada especialmente à questão da demarcação de fronteiras claras e diferenciação em relação ao outros domínios de saber (Demo, 1985), à construção de critérios internos de legitimação (o que faz com que a ciência se justifique por si mesma) e a interpretação da heteronomia (e, portanto, da inserção social da ciência) como algo a ser evitado, pois ela estaria relacionada à fragmentação e ao conflito de ideias, característica típica de ciências pré-paradigmáticas (Kuhn, 1987).

O predomínio dessa compreensão levou a uma interpretação quase unânime de que a autonomia científica é algo a ser buscado. Isso acaba por ser absorvido nas práticas e se torna um verdadeiro exemplar, no sentido estabelecido por Kuhn (1987), sendo assumido como algo dado. Disso resulta a interpretação de que as ciências que têm uma maior heteronomia, ou seja, uma maior hibridação com outros campos de saberes, como as práticas, a política ou, ainda, a religião, seriam ciências mais frágeis, nas quais imperam uma confusão teórica e uma pluralidade de visões que impedem a estabilização e o avanço em termos científicos. A Administração se enquadra nessa categoria, assim como outras ciências sociais aplicadas, sendo, então, por muito tempo, e até hoje, considerada por muitos uma ciência subsidiária de outros campos disciplinares, incapaz de garantir uma autonomia suficiente para se afirmar como ciência.

Porém, o debate atual no campo da própria sociologia da ciência vem colocar em xeque essa dicotomia entre autonomia e heteronomia. Os estudos recentes desnaturalizam esse ideal de ciência pura e se concentram no fazer científico, mostrando a ciência não apenas como um saber, mas como uma instituição social (Pestre, 2006) que se constrói por meio de um conjunto de associações (Latour, 2012), uma rede, um mangle of practices (Pickering \& Guzic, 2008) que se produz na interface de perspectivas, conexões e agenciamentos entre humanos e não humanos e na hibridação entre cientistas, expertos e pessoas comuns. Em particular nas ciências sociais, esse debate se fortalece com a virada pragmática, sobretudo na França, a partir dos anos 1990 (Boltanski \& Thévenot, 2006; Cefaï \& Terzi, 2012; Chateauraynaud, 2011; Frega, 2016; Latour, 2012).

Esse movimento centra-se na interface entre ciência e as práticas sociais, tomando a relação autonomia-heteronomia na ciência sob uma perspectiva dialógica e entendendo que a ciência social é um saber situado, que precisa estar atento às práticas, às experiências, às situações de provas confrontadas pelas pessoas ordinárias nos processos de enfrentamento de situações problemáticas da vida cotidiana. São nesses embates que o social se transforma e se estabiliza, portanto é fundamental que o cientista social imploda definitivamente a torre de marfim. Seu papel maior passa a ser de seguir os atores, já que estes são considerados capazes de reflexividade e de construir suas próprias teorias. Assim, a virada pragmática na sociologia das ciências e nas ciências sociais clama por um repensar da ciência e das próprias práticas científicas. No lugar de um gênio cientista que mora no laboratório e tem ideias brilhantes, pai das intuições científicas, coloca-se um(a) cientista social que segue as pistas de uma complexa rede de conexões e agenciamentos que se formam cotidianamente no reino da vida comum. Cai o castelo da ciência, desvelam-se os laboratórios da vida cotidiana.

Nessa perspectiva, é fundamental ressaltar o papel precursor do trabalho de John Dewey e a sua noção de social inquiry. Nos seus trabalhos, Dewey, já no início do século XX, desnaturaliza esse ideal de ciência, buscando religar a produção de conhecimento e os processos de construção social. Para Dewey (1938), os problemas de qualquer investigação social devem emergir de situações existenciais problemáticas. 0 autor nos incita a questionar a forma clássica de fazer ciência, que não problematiza o real e que toma por posto (fato) que os problemas existem a priori, e que necessitam de soluções. Dewey (1938) nos convida a constituir os nossos objetos de investigação, de maneira conjunta com os atores que estão envolvidos nas "situações problemáticas” do cotidiano. Dessa maneira, ele aproxima o conhecimento científico dos saberes práticos, a verdade do valor, a ciência da política. Para Dewey, o conhecimento é coconstruído na relação com o mundo. Isso implica, como afirma Zask (2004), um processo de interobjetivação que ocorre num vai e vem entre a démarche intelectual e os fenômenos, e que leva em conta, metodologicamente e na prática, uma pluralidade de visões, interesses, desejos e aspirações. Essa noção vem sendo retomada atualmente por vários autores nas ciências sociais (Cefaï, 2017; Joseph, 2004; Zask, 2004), que buscam evidenciar as relações entre pesquisa pública e fortalecimento de uma cultura democrática, mostrando que o impacto social da ciência vai muito além da sua funcionalidade em termos de aplicação, e envolve também a capacidade daqueles que têm acesso e são capazes de produzir conhecimento, de agir sobre a realidade em que vivem e transformá-la, ou seja, a sua capacidade de instituir (Bauman, 2000; Castoriadis, 1997; Lefort, 1981).

E o que tudo isso tem a ver com a Administração? Tendo em vista as considerações feitas e inspirando-se em 
Santos (1988), pode-se dizer que aquilo que se considerava fraqueza na Administração e que constantemente era motivo de questionamento e de rebaixamento desta em relação às demais ciências se coloca hoje como oportunidade de avanço científico. A Administração é tradicionalmente uma ciência das práticas, uma ciência interdisciplinar, uma ciência que se faz nos diversos laboratórios da vida, seja nos espaços públicos, das organizações, das políticas públicas, das redes. A Administração é uma ciência essencial ao processo de instituir e de transformar realidades. Nesse sentido, o olhar sobre o objeto da Administração também se amplia, saindo dos limites do mundo organizacional e adentrando o universo das ações coletivas, que envolvem maior ou menor grau de coordenação.

Diante disso, novas perspectivas e passarelas se abrem nessa relação entre ciência da Administração e sociedade, e também para a construção de uma ciência que faça sentido, produzindo consequências que estejam em consonância com as inúmeras demandas de seu tempo. Entretanto, para que se possa aproveitar esse potencial, é preciso que a ciência da Administração se conecte cada vez mais com esse real em movimento, com as suas necessidades e demandas, se abrindo para novas experimentações: epistêmicas, teóricas e metodológicas.

\section{IMPACTO SOCIAL DA PESQUISA EM ADMINISTRAÇÃO NO BRASIL}

Tendo em vista os debates travados no âmbito da sociologia da ciência, a pesquisa científica passa a ser objeto de questionamento em seus objetivos, estratégias, métodos e efeitos. A principal ênfase recai sobre a sua razão de ser e sobre os impactos sociais advindos de seus resultados. Cabrera (2015) discorre sobre algumas questões que deveriam ser pauta de tomadores de decisão pública acerca da ciência. Tais questões incidiriam sobre a real utilidade de seus resultados em termos sociais, econômicos, culturais e ambientais, seu atendimento às necessidades mais prementes da sociedade, além de sua incidência na produção e na difusão de novos conhecimentos nos processos sociais.

Apesar da importância de se discutir a relevância da ciência na atualidade, considerando as turbulências sociais, econômicas e ambientais que o mundo atravessa, os organismos internacionais e a própria comunidade científica parecem não tratar o assunto com a atenção devida. De acordo com Cabrera (2015), isso pode estar associado à carência de mecanismos consolidados que possam dar conta do impacto social da pesquisa.
De fato, falar em impacto social não é uma tarefa fácil, especialmente na área de Administração, na qual o conhecimento é intangível e de difícil medição, o que acaba por restringi-lo a medidas indiretas. Além disso, diversos são os fatores envolvidos, incluindo, entre outros, a maneira como esse conhecimento é produzido e como é utilizado (Guisado, Cabrera, \& Cortes, 2010).

Sobre essa questão, Wood, Costa, Lima e Guimarães (2016) citam o relatório de 2013 da Association to Advance Collegiate Schools of Business (AACSB), o qual define como indicadores indiretos de impacto as publicações em periódicos qualificados, o número de downloads de artigos, as premiações de pesquisas e de trabalhos científicos, as citações na mídia, a adoção de artigos científicos em programas de cursos, entre outros. As medidas diretas estariam associadas à possibilidade de alterações na realidade, a partir da adoção de novas práticas e abordagens operacionais por organizações e da participação na formulação de políticas públicas, sendo essas últimas mais difíceis de constatar.

No Brasil, lacunas que indicam a necessidade de aumento no impacto social dos principais cursos de pós-graduação foram identificadas por Wood et al. (2016). Considerando os requisitos avaliados pela Capes, os indicadores utilizados pelos autores foram indiretos, medindo a formação de doutores, o índice $\mathrm{H}$ institucional, a partir da utilização do software Publish or Perish (PoP) sobre a base do Google Scholar e as citações na mídia especializada na área de negócios. Tratando desse aspecto, Alcadipani (2017) argumenta que mesmo o impacto social indireto das pesquisas no país é incipiente, considerando que raros são os trabalhos que trazem contribuições acadêmicas efetivas.

Como se verifica em vários trabalhos sobre o produtivismo no Brasil (Alcadipani, 2011, 2017; Godoi \& Xavier, 2012; Machado \& Bianchetti, 2011; Patrus, Dantas, \& Shigaki, 2015), a lógica do publish or perish anglo-saxão passou a dominar o campo acadêmico da Administração, onde a publicação em periódicos qualificados acaba se configurando como o principal vetor para analisar cursos, professores e alunos. Logo, o escrever e o publicar passam a representar a prática corrente e a principal métrica acadêmica e, por consequência, a medida preponderante do impacto social da pesquisa.

Essa lógica, caracterizada "pela excessiva valorização da quantidade da produção acadêmica” (Patrus et al., 2015, p. 1) sem preocupação com a qualidade já havia sido antecipada por Tragtenberg (1979) em sua obra sobre a "delinqüência acadêmica" (p. 7), na qual compara a avaliação da produção acadêmica a um “metro para medir o sucesso universitário". Com isso, há o risco de que as pesquisas tenham um fim em si mesmas e os acadêmicos produzam para si próprios, transformando o objetivo da pesquisa em fazer pontos (Godoi \& Xavier, 2012), distanciando-se cada vez 
mais dos reais problemas da sociedade e de "um pensamento original a partir de uma prática acadêmica que gere significado efetivo" (Alcadipani, 2017, p. 407).

Duas décadas mais tarde, Bertero, Caldas e Wood (1999) também observaram na produção acadêmica em Administração no Brasil, gerada na e para a própria academia, uma baixa preocupação com a aplicabilidade e com os problemas concretos. Somam-se a isso suas bases referenciais alicerçadas fundamentalmente na produção estrangeira, notadamente norteamericana, reproduzindo seus modelos e modismos (Bertero \& Keinert, 1994).

Tal lógica continua a ser observada nos dias atuais, e essa "fábrica de papers" (Alcadipani, 2017, p. 407) - que pouco dialoga com os complexos problemas públicos em que estamos mergulhados -, embora muito criticada, se fortalece cada vez mais num ambiente institucional e internacional da science as business, comandado por grandes corporações e editoras, suas certificações, índices e métricas. Nesse contexto, a questão há décadas posta por Tragtenberg (1979) sobre a responsabilidade social da ciência da Administração e seu compromisso com os reais problemas do nosso país ainda se coloca como extremamente relevante.

Tornando-se cada vez mais protocolar, a pesquisa científica perde espaço para outras instâncias que produzem conhecimento e saberes fora da academia. Como antecipou Tragtenberg (1979), “se os estudantes procuram conhecer os espíritos audazes de nossa época, é fora da universidade que irão encontrá-los. A bem da verdade, raramente a audácia caracterizou a profissão acadêmica" (p. 4). Isso também porque a ausência de responsabilização pelas finalidades sociais daquilo que se produz tem como efeito a formação de pesquisadores pouco críticos e reflexivos, que tendem a agir como pessoas reativas, no dizer de Guerreiro Ramos, pois acabam por admitir um sistema que reforça comportamentos e práticas que sustentam uma racionalidade específica (Ramos, 1984, p. 5).

Nessa lógica, há um afastamento da ideia de Bergson, do início do século XX, retomada por Tratenberg (1979, p. 7), que advertia sobre a "a necessidade do homem agir como homem de pensamento e pensar como homem de ação", já que a "delinquência acadêmica" leva a uma separação entre o fazer e o pensar. Nesse sentido, problematizar as realidades configura-se, para o autor, como um ato político, uma forma de ação ou uma prática intrínseca da responsabilidade social dos intelectuais. Para Tratenberg (1979) “a valorização de um homem culto reside exatamente na importância que representa para ele a defesa de valores como a cidadania, manifestada não apenas em seu discurso, mas em sua própria existência” (p. 7), em suas práticas.
Atualmente ainda é muito comum vermos estudos que visam, em primeiro lugar, responder aos estímulos gerados pelas próprias agências de fomento ou à lógica editorial e, para tanto, acabam por se adequar a essas exigências de maneira reativa. Disso resultam trabalhos que pouco problematizam ou consideram as especificidades e demandas locais, que dificilmente aliam ensino, pesquisa e extensão e que resultam muito mais de um esforço individual do pesquisador e de suas inquietações do que de um trabalho coletivo, coconstruído com os próprios sujeitos pesquisados.

\section{QUAIS AS PERSPECTIVAS?}

Partindo do que foi discutido, fica explícito que o debate sobre o impacto social da pesquisa em Administração vai muito além da medição de indicadores; faz-se necessário rediscutir a própria prática da pesquisa, o fazer ciência. Isso se torna mais premente diante dos graves problemas socioambientais e éticos que vivemos, fazendo-nos repensar os modelos de desenvolvimento e os estilos de vida (Lévesque, 2009; Vieira, 2009). Nesse quadro, espera-se que a ciência seja um lócus de experimentação, de construção de novos caminhos e repostas para os dilemas do seu tempo. No campo da Administração no Brasil, essa demanda é ainda mais imperativa diante da crise institucional e de legitimidade que enfrentamos, tanto no mundo corporativo quanto na administração pública. Que a ciência da Administração faça sentido não é mais um luxo, é uma urgência!

Observa-se que tal preocupação já está presente há algum tempo nas reflexões e debates de autores que pensam a ciência da Administração no Brasil, tanto no âmbito epistemológico (Paula, 2015; Serva, 2013) quanto no metodológico (Bispo \& Godoy, 2014; Godoi, Bandeira-De-Mello, \& Silva, 2006; Sá \& Mattos, 2016). Esse debate levanta a necessidade de construção de passarelas entre diferentes matrizes epistêmicas e afirma que a pluralidade teórica e metodológica típica da disciplina é um estímulo para se pensar novos caminhos, formatos e desenhos de pesquisa.

Essas constatações fazem emergir a importância da relação entre a produção de conhecimento, a responsabilidade axiológica do pesquisador (valores), suas visões de mundo e suas práticas de pesquisa (Hill, 1984; Paula, 2015).Tudo isso abre espaço para novas experimentações na pesquisa em Administração e para estudos interdisciplinares, que concebam e caminhem por novas avenidas epistemológicas, teóricas e metodológicas, que problematizem e busquem compreender fenômenos pouco 
explorados. Apesar de não estarem em evidência, tais estudos são mais comuns do que se pensa, e são fruto das escolhas e ações de inúmeros professores e pesquisadores neste Brasil que colocam luz e agem sobre fenômenos que, embora sejam relevantes, são pouco estudados pelo mainstream da Administração. Seriam muitos os que mereceriam ser citados, não só nas universidades mais consagradas.

Assim, observa-se múltiplas perspectivas e infinitas possibilidades para se produzir pesquisas em Administração no Brasil que façam mais sentido. Porém, isso não quer dizer que a tarefa seja fácil. É a partir da experiência e nas suas consequências cotidianas que percebemos a satisfação em se fazer pesquisa de outra forma. Isso nos permite afirmar que, apesar da aparente evidência de que caminhamos para uma uniformização da pesquisa científica em Administração e dos seus efeitos - que parecem se tornar cada vez mais protocolares e reativos -, na prática, nós, pesquisadores, temos sempre a escolha de seguir nosso próprio caminho. E as práticas contêm em si essa magia de mudar as realidades.

\section{REFERÊNCIAS}

Alcadipani, R. (2011). Resistir ao produtivismo: Uma ode à perturbação acadêmica. Cadernos EBAPE.BR, 9(4), 1174-1178. doi:10.1590/S167939512011000400015

Alcadipani, R. (2017). Periódicos brasileiros em inglês: A mímica do publish or perish "global". RAE-Revista de Administração de Empresas, 57(4), 405-411. doi:10.1590/s0034-759020170410

Bauman, Z. (2000). Em busca da política. Rio de Janeiro, RJ: Zahar.

Bertero, C. O., Caldas, M. P., \& Wood, T., Jr. (1999). Produção científica em administração de empresas: Provocações, insinuações e contribuições para um debate local. RAC-Revista de Administração Contemporânea, 3(1), 147-178. doi:10.1590/S141565551999000100009

Bertero, C. O., \& Keinert, T. M. M. (1994). A evolução da análise organizacional no Brasil. RAE-Revista de Administração de Empresas, 34(3), 81-90. doi:10.1590/S0034-75901994000300007

Bispo, M. de S., \& Godoy, A. S. (2014). Etnometodologia: Uma proposta para pesquisa em estudos organizacionais. Revista de Administração da UNIMEP, 12(2), 108-135. doi:10.15600/1679-5350/ rau.v12n2p108-135

Boltanski, L., \& Thévenot, L. (2006). On justification: Economies of worth. Oxford, USA: Princeton University Press.

Bourdieu, P. (2001). Science de la science et réflexivité. Paris, France: Raisons d'Agir.

Cabrera, S. F. M. (2015). Medir el impacto social de la ciencia y la tecnología: ¿Viable o utópico? Revista Iberoamericana de Ciencia, Tecnología y Sociedad, 10 (Supl. 1), 57-59.
Castoriadis, C. (1997). Democracy as procedure and democracy as regime. Constellations, 4(1), 1-18. doi:10.1111/1467-8675.00032

Cefaï, D. (2017). Públicos, problemas públicos, arenas públicas...: O que nos ensina o pragmatismo (Parte 1). Novos Estudos, (107), 187-213.

Cefaï, D., \& Terzi, C. (2012). L'expérience des problèmes publics. Paris, France: Perspectives Pragmatistes.

Chateauraynaud, F. (2011). Argumenter dans un champ de forces: Essai de balistique sociologique. Paris, France: Petra.

Demo, P. (1985). Metodologia científica em ciências sociais. São Paulo, SP: Atlas.

Dewey, J. (1938). The theory of inquiry. New York, USA: Holt, Rinehart \& Wiston.

Frega, R. (2016). Quést-ce qu“une pratique? In F. Chateuraynaud, \& Y. Cohen, Histoires pragmatiques: Raisons pratiques (pp. 321-347). Paris, France: Editions de l'EHESS.

Godoi, C. K., Bandeira-De-Mello, R., \& Silva, A. B. da. (2006). Pesquisa qualitativa em estudos organizacionais: Paradigmas, estratégias e métodos. São Paulo, SP: Saraiva.

Godoi, C. K., \& Xavier, W. G. (2012). 0 produtivismo e suas anomalias. Cadernos EBAPE.BR, 10(2), 456-465. doi:10.1590/S167939512012000200012

Guisado, Y. M., Cabrera, F. M. S., \& Cortés, J. N. (2010). Aproximaciones a la evaluación del impacto social de la ciencia, la tecnología y la innovación. ACIMED, 21(2), 161-183.

Hill, M. R. (1984). Epistemology, axiology, and ideology in sociology. MidAmerican Review of Sociology, 9(2), 59-77.

Joseph. I. (2004). L'athlete moral et l'enquêteur modeste. In B. Karsenti, $\& \mathrm{~L}$. Queré, La croyance et l'enquete aux sources du pragmatisme (pp. 19-52). Paris, France: Raisons Pratiques.

Kuhn, T. (1987). A estrutura das revoluções científicas. São Paulo, SP: Perspectiva.

Latour, B. (2012). Reagregando o social: Uma introdução à teoria do ator-rede. Salvador, BA: Edufba.

Lefort, C. (1981). L'invention democratique. Paris, France: Fayard.

Lévesque, B. (2009). Economia plural e desenvolvimento territorial na perspectiva do desenvolvimento sustentável: Elementos teóricos de sociologia econômica e de socioeconomia. Política \& Sociedade, 8(14), 107-144. doi:10.5007/2175-7984.2009v8n14p107

Machado, A. M. N., \& Bianchetti, L. (2011). (Des)Fetichização do produtivismo acadêmico: Desafios para o trabalhador-pesquisador RAE-Revista de Administração de Empresas, 51(3), 244-254. doi:10.1590/So034-75902011000300005

Merton, R. K. (1967). Sociologia do conhecimento. In A. R. Bertelli, M. G. S. Palmeira, \& O. G. Velho (Orgs.), Sociologia do conhecimento (pp. 81-125). Rio de Janeiro, RJ: Zahar.

Patrus, R., Dantas, D. C., \& Shigaki, H. B. (2015). O produtivismo acadêmico e seus impactos na pós-graduação stricto sensu: Uma ameaça à solidariedade entre pares? Cadernos EBAPE.BR, 13(1), 1-18. doi:10.1590/1679-39518866

Paula, A. P. P. de. (2015). Repensando os estudos organizacionais: Para uma nova teoria do conhecimento. São Paulo, SP: FGV. 
Pestre, D. (2006). Introduction aux science studies. Paris, France: La Découverte.

Pickering, A., \& Guzic, K. (Eds.). (2008). The mangle in practice: Science, society and becoming. London, UK: Duke University Press.

Ramos, A. G. (1984). Modelos de homem e teoria administrativa. RAPRevista de Administração Pública, 18(2), 3-12.

Sá, M. G., \& Mattos, P. L. C. L. (2016). De pequenos negócios de feira à metodologia científica: Dúvidas herdadas de experiências de pesquisa. Farol - Revista de Estudos Organizacionais e Sociedade, 3(7), 605-644.

Santos, B. de S. (1988). Um discurso sobre as ciências. Coimbra, Portugal: Edições Afrontamento.

Serva, M. (2013). O surgimento e o desenvolvimento da epistemologia da administração: Inferências sobre a contribuição ao aperfeiçoamento da teoria administrativa. Revista Gestão Organizacional, 6(3), 51-64.
Tragtenberg, M. (1979). A delinquência acadêmica: O poder sem saber e o saber sem poder. São Paulo, SP: Rumo.

Vieira, P. F. (2009). Políticas ambientais no Brasil: Do preservacionismo ao desenvolvimento territorial sustentável. Política \& Sociedade, 8(14), 27-75. doi:10.5007/2175-7984.2009v8n14p27

Weber, M. (1973). O político e o cientista. Lisboa, Portugal: Editorial Presença.

Wood, T., Jr., Costa, C. C. M., Lima, G. de M. R., \& Guimarães, R. C. (2016). Impacto social: Estudo sobre programas brasileiros selecionados de pós-graduação em administração de empresas. RAC-Revista de Administração Contemporânea, 20(1), 21-40. doi:10.1590/19827849 rac20161842

Zask, J. (2004). L'enquete sociale comme inter-objectivation. In B. Karsenti, \& L. Queré, La croyance et l'enquete aux sources du pragmatisme (pp. 141-163). Paris, France: Raisons Pratiques. 